\title{
Regulation of $\left[\mathrm{Ca}^{2+}\right]_{i}$ oscillations and mitochondrial activity by various calcium transporters in mouse oocytes
}

\author{
Feng Wang ${ }^{1,2} \mathbb{B}$, Ang Li ${ }^{2}$, Tie-Gang Meng ${ }^{1,2}$, Le-Yun Wang ${ }^{2}$, Li-Juan Wang ${ }^{2}$, Yi Hou ${ }^{2}$, Heide Schatten³ \\ Qing-Yuan Sun ${ }^{1,2^{*}}$ and Xiang-Hong $\mathrm{Ou}^{1 *}$
}

\begin{abstract}
Oocyte activation inefficiency is one of the reasons for female infertility and $\mathrm{Ca}^{2+}$ functions play a critical role in the regulation of oocyte activation. We used various inhibitors of $\mathrm{Ca}^{2+}$ channels located on the membrane, including sarcoplasmic/ endoplasmic reticulum $\mathrm{Ca}^{2+}$ ATPases (SERCAs, the main $\mathrm{Ca}^{2+}$ pumps which decrease the intracellular $\mathrm{Ca}^{2+}$ level by refilling $\mathrm{Ca}^{2+}$ into the sarcoplasmic reticulum), transient receptor potential (TRP) ion channel subfamily member 7 (TRPM7, a Ca ${ }^{2+} / \mathrm{Mg}^{2+}$-permeable non-selective cation channel), T-type $\mathrm{Ca}^{2+}$ channels and calcium channel Orai1, to investigate their roles in $\left[\mathrm{Ca}^{2+}\right]_{\mathrm{i}}$ oscillation patterns and mitochondrial membrane potential during oocyte activation by real-time recording. Our results showed that SERCAs, TRPM7 and T-type $\mathrm{Ca}^{2+}$ channels were important for initiation and maintenance of $\left[\mathrm{Ca}^{2+}\right]_{i}$ oscillations, which was required for mitochondrial membrane potential elevation during oocyte activation, as well as oocyte cytoskeleton stability and subsequent embryo development. Increasing the knowledge of calcium transport may provide a theoretical basis for improving oocyte activation in human assisted reproduction clinics.
\end{abstract}

Keywords: Oocyte activation, $\left[\mathrm{Ca}^{2+}\right]$ i oscillations, Mitochondrial membrane potential, Assisted reproductive technology (ART)

\section{Introduction}

According to reports by the World Health Organization in 2016, at least one of ten couples in developed countries cannot have children within 5 years of marriage, half of which are due to female infertility [1]. Oocyte activation inefficiency is a major problem causing female infertility [2]. Oocytes are arrested at metaphase of the second meiosis until fertilization takes place. Directly following sperm penetration, oocyte activation begins with a series of crucial steps triggered by periodical repetitive increases and decreases of intracellular $\mathrm{Ca}^{2+}\left(\left[\mathrm{Ca}^{2+}\right]_{\mathrm{i}}\right)$ concentrations known as $\left[\mathrm{Ca}^{2+}\right]_{i}$ oscillations $[3,4]$. Although $\left[\mathrm{Ca}^{2+}\right]_{\mathrm{i}}$

\footnotetext{
*Correspondence: sunqy@ioz.ac.cn; ouxianghong2003@163.com ${ }^{1}$ Fertility Preservation Lab, Reproductive Medicine Center, Guangdong Second Provincial General Hospital, Guangzhou 510317, China Full list of author information is available at the end of the article
}

oscillations are required for oocyte activation [5], very little is known about which $\mathrm{Ca}^{2+}$ transporter participates in producing $\left[\mathrm{Ca}^{2+}\right]_{\mathrm{i}}$ oscillations during oocyte activation.

The importance of $\mathrm{Ca}^{2+}$ functions in the regulation of oocyte activation is increasingly being recognized [6]. There are many important channel proteins involved in $\mathrm{Ca}^{2+}$ transport in oocytes. $\mathrm{Ca}^{2+}$ transporters on the plasma membrane can be controlled by voltage, ligand, second messengers, $\mathrm{Ca}^{2+}$ concentration, or other interactions [7]. $\mathrm{Ca}^{2+}$ influx into the cytoplasm is mediated by a diverse population of $\mathrm{Ca}^{2+}$ transporters exhibiting significant diversities in their gating and activation mechanisms. Once the oocyte is activated, the $\left[\mathrm{Ca}^{2+}\right]_{i}$ oscillations are produced by simultaneous intracellular $\mathrm{Ca}^{2+}$ storage release and the extracellular $\mathrm{Ca}^{2+}$ influx [8]. Hence, it is important to elucidate the molecular 
mechanisms of $\left[\mathrm{Ca}^{2+}\right]_{\mathrm{i}}$ oscillations at activation. According to our previous research, mitochondria, main organelles for energy production in the cell, are involved in producing $\left[\mathrm{Ca}^{2+}\right]_{\mathrm{i}}$ oscillations during oocyte activation [9]. Since $\mathrm{Ca}^{2+}$ regulates mitochondria activity in cardiomyocytes [10], we thus believe that $\left[\mathrm{Ca}^{2+}\right]_{\mathrm{i}}$ oscillations in the cytoplasm will have similar effects in oocytes. At present, the transporters involved in the regulation of $\left[\mathrm{Ca}^{2+}\right]_{\mathrm{i}}$ oscillations and mitochondria activity have not been fully determined.

In this study, specific inhibitors for different $\mathrm{Ca}^{2+}$ transporters were introduced to detect the $\left[\mathrm{Ca}^{2+}\right]_{\mathrm{i}}$ oscillation patterns and mitochondria membrane potential dynamic changes, in order to evaluate the role of $\mathrm{Ca}^{2+}$ transporters in oocyte activation. Studying the function and regulatory mechanisms of these transporters will have significant importance for both understanding oocyte activation mechanisms and for improving clinical assisted reproductive technologies (ART).

\section{Materials and methods}

\section{Ethics statement}

Female ICR mice at 8 weeks old were purchased from the Beijing Vital River Laboratory Animal Technology Co., Ltd. All mice were handled in accordance with the institutional animal care policies of the Institute of Zoology, Chinese Academy of Sciences. Mice were maintained under a 12-h light and 12-h darkness cycle in a specific pathogen-free stage at the Central Animal Laboratory of the Institute of Zoology, Chinese Academy of Sciences. The Laboratory Animal Care and Use Committee of the Institute of Zoology approved this study (The ethics committee approval number: SYXK 2018-0021).

\section{In vitro transcription of CRNA}

The cytoplasmic spindle formation and F-actin meshwork were investigated by live imaging of $\mathrm{F}$-actin with mRNA encoding b5-tubulin-GFP $[11,12]$ and UtrCH-eGFP $[11,13]$ as previously described. Templates of in vitro transcription from constructed plasmids were obtained by PCR with F and R primers. PCR products were diluted in RNAse-free water. cRNA transcripts were synthesized in vitro with T7 RNA polymerase mMESSAGE mMACHINE T7 kit (Ambion, Life. Co, Calsbad, CA, USA). Poly(A) tail was added to the sequence end by polymerase tailing kit (PAP5104, Lucigen, Beijing, China). The RNA solutions were then stored at $-80^{\circ} \mathrm{C}$ in a final concentration of $400 \mu \mathrm{g} / \mathrm{mL}$ until further use. Approximately $50 \mathrm{pl}$ of RNA solution was injected into each GV oocyte.

\section{Oocyte collection and partheno-activation}

Female mice were injected with $10 \mathrm{IU}$ pregnant mare serum gonadotropin (PMSG, Ningbo Hormone Product Co. Ltd., Cixi, China). After 44 to $48 \mathrm{~h}$, the GV oocytes were collected by ovarian mincing. Female mice were injected with $10 \mathrm{IU}$ PMSG followed 44 to $48 \mathrm{~h}$ later by injection of $10 \mathrm{IU}$ human chorionic gonadotropin (hCG, Ningbo Hormone Product Co. Ltd., Cixi, China). After 15 $\mathrm{h}$ of hCG, ovulated MII oocytes were collected and denuded in $1 \mathrm{mg} / \mathrm{ml}$ hyaluronidase. $\left[\mathrm{Ca}^{2+}\right] \mathrm{i}$ oscillations were induced by $10 \mathrm{mM}$ strontium chloride $\left(\mathrm{SrCl}_{2}, 10,025-70-4\right.$, Sangon Biotech, Shanghai, China) in $\mathrm{Ca}^{2+}$-free CZB culture medium containing various $\mathrm{Ca}^{2+}$ channel modulators for as long as $4 \mathrm{~h}$. After partheno-activation, embryos were moved into KSOM (MR-106, Merck Millipore, USA) for further culture, and pronuclear formation and cleavage were observed.

The details of $\mathrm{Ca}^{2+}$ channel blockers used in the study are described below: Thapsigargin $(10,522$, Cayman, Michigan, USA), a SERCAs inhibitor [14] stored in DMSO in $10 \mathrm{mM}$, with gradient working concentrations of $0.5,1$, and $10 \mu \mathrm{M}$; NS-8593 (N-195, Alomone, Jerusalem BioPark, Jerusalem, Israel), a TRPM7 inhibitor [15], stored in DMSO in $10 \mathrm{mM}$, with working gradient concentrations of $0.1,1$, and $5 \mu \mathrm{M}$; Mibefradil (Mib, HY15553, MCE, NJ 08852, USA), a T-type $\mathrm{Ca}^{2+}$ channels blocker [16], stored in water in $10 \mathrm{mM}$, with working gradient concentrations of $0.5,5$, and $10 \mu \mathrm{M}$; GSK7975A (HY12507, MCE, NJ 08852, USA), an Orai1blocker [17], stored in DMSO in $10 \mathrm{mM}$, with gradient concentrations of $10,100 \mu \mathrm{M}$, and $1 \mathrm{mM}$. All inhibitors were added to $\mathrm{Ca}^{2+}$-free $\mathrm{CZB}$ incubating medium with an equal concentration of DMSO as the control for $4 \mathrm{~h}$.

\section{The GV oocyte microinjection}

The M2 medium and M16 medium containing $2.5 \mu \mathrm{M}$ milrinone were prepared and warmed to $37^{\circ} \mathrm{C}$. Milrinone is a phosphodiesterase inhibitor that maintains meiotic arrest once oocytes are removed from the follicles [18]. Micro-drops each containing $20 \mu \mathrm{l}$ M16 medium with milrinone were prepared in a dish and overlaid with mineral oil. Injection pipettes were made by pulling borosilicate-glass capillary with filament in a mechanical puller. We used a Flaming-Brown micropipette puller (Model P-97) with the following settings: $P=$ $540, \quad$ Heat $=300, \quad$ Pull $=130, \quad$ Vel $=100, \quad$ Time $=150$. Microinjection platform was prepared by placing a $10 \mu \mathrm{l}$ micro-drop of M2 medium with milrinone on a chamber slide, and the drop was covered with mineral oil and placed on the microscope stage. Injection and holding pipettes were placed into the drop of M2 medium with milrinone. cRNA microinjection of GV oocytes was performed with Narishige micromanipulators (Narishige Inc., Sea Cliff, NY) under a Nikon TE 200 (Nikon UK Ltd., Kingston upon Thames, Surrey, UK) and finished within $30 \mathrm{~min}$. After cRNA injection, the oocytes were arrested at the GV stage in M16 medium containing 
$2.5 \mu \mathrm{M}$ milrinone for $4 \mathrm{~h}$. Then the oocytes were transferred to M16 medium and cultured under mineral oil at $37^{\circ} \mathrm{C}$, in an atmosphere of $5 \% \mathrm{CO}_{2}$ in air for $14 \mathrm{~h}$ in vitro maturation.

\section{Real-time recording of $\left[\mathrm{Ca}^{2+}\right] \mathrm{i}$ changes}

Oocyte $\left[\mathrm{Ca}^{2+}\right]_{\mathrm{i}}$ oscillations were detected using $2 \mu \mathrm{g} / \mathrm{mL}$ Fluo-4 AM (488 nm excitation, $525 \mathrm{~nm}$ emission) in the partheno-activation solution. Real-time images of $\left[\mathrm{Ca}^{2+}\right]_{i}$ changes after partheno-activation of oocytes which were co-incubated with various $\mathrm{Ca}^{2+}$ channel modulators were obtained using a time-lapse confocal laser microscope (UltraVIEW-VoX; PerkinElmer, MA, USA) and recorded at 2 frames per minute. $\left[\mathrm{Ca}^{2+}\right]_{\mathrm{i}}$ intensity was detected using an argon laser. Volocity Software was used to analyze fluorescence intensity.

\section{Real-time recording of oocyte mitochondrial potential}

In our study, we set out to confirm the $\left[\mathrm{Ca}^{2+}\right]_{\mathrm{i}}$ oscillations regulatory function in mitochondrial activity during oocyte activation. Oocytes were denuded and pre-incubated in M2 culture medium (M7167, Sigma-Aldrich, USA) with $2 \mu \mathrm{g} / \mathrm{mL}$ JC-1 (C2005, Beyotime, Beijing, China), a cell permeable voltage-sensitive fluorescent mitochondrial dye, for $15 \mathrm{~min}$. In order to reduce the toxicity of JC-1 for long-term observation using laser confocal microscope, we reduced the concentration of JC-1 to $0.5 \mu \mathrm{g} / \mathrm{ml}$ in the activating solution. Briefly, the lower potential mitochondria were imaged as JC-1 monomer emitting in green (488 nm excitation, $561 \mathrm{~nm}$ emission), and energized high potential mitochondria were imaged in aggregated JC-1 that emits in red (488 $\mathrm{nm}$ excitation, $561 \mathrm{~nm}$ emission) as fluorescence transporters. Oocyte mitochondrial potential dynamic changes after treatment with various $\mathrm{Ca}^{2+}$ channel modulators were recorded after partheno-activation using a time-lapse confocal laser microscope (UltraVIEWVoX; PerkinElmer, MA, USA) at identical magnification and gain settings throughout the experiments. A software Volocity was used to analyze fluorescence intensity.

\section{Statistical analysis}

All experiments were conducted at least three times. At least 40 oocytes were collected and examined in each experiment and experiments were repeated more than three times. More than a total of 120 oocytes were examined in each group. We presented information of samples with Means and Standard Deviations (SD). Results were analyzed by SPSS 19.0. The significance of differences among groups was analyzed by the Chi-square test, and $p$ values less than 0.05 were considered statistically significant.

\section{Results}

Inhibitors of $\mathrm{Ca}^{2+}$ channels affect the efficiency of oocyte activation

We firstly examined the dose-dependent effects of inhibitors of SERCAs, TRPM7, T-type $\mathrm{Ca}^{2+}$ channels and Orail on the efficiency of $\mathrm{SrCl}_{2}$-induced oocyte parthenoactivation and found a suitable concentration. The percentages of survival oocytes showed clear cell membrane and high cytoplasmic refraction after activation, pronuclear formation and 2-cell cleaved embryos as shown in Table 1. We applied Thapsigargin (Tha) with gradient concentrations of $0.5,1$, and $10 \mu \mathrm{M}$. When its concentration rose to $10 \mu \mathrm{M},[\mathrm{Ca} 2+] \mathrm{i}$ would rise slowly, and oocytes died during the activation process. NS-8593 was applied with gradient concentrations of $0.1,1$, and

Table 1 Effect of calcium channel inhibitors on oocyte parthenogenetic activation

\begin{tabular}{|c|c|c|c|c|c|c|}
\hline Inhibitor & Concentration & No. oocytes & Repeats & PA & PN & 2-Cell \\
\hline Ctrl & & 240 & 5 & $98.33 \pm 1.24 \%$ & $93.25 \pm 5.32 \%$ & $82.90 \pm 7.53 \%$ \\
\hline \multirow[t]{3}{*}{ Tha } & $0.5 \mu \mathrm{M}$ & 240 & 5 & $84.2 \pm 5.72 \%$ & $65.7 \pm 9.56 \% *$ & $67.6 \pm 7.59 \%$ \\
\hline & $1 \mu \mathrm{M}$ & 240 & 5 & $66.2 \pm 9.24 \%$ & $42.1 \pm 8.56 \% \%^{*}$ & $26.1 \pm 12.45 \% *$ \\
\hline & $10 \mu \mathrm{M}$ & 240 & 5 & 0 & $x$ & $x$ \\
\hline \multirow[t]{3}{*}{ NS-8593 } & $0.1 \mu \mathrm{M}$ & 240 & 5 & $83.3 \pm 6.28 \%$ & $75.2 \pm 9.57 \%$ & $86.7 \pm 7.50 \%$ \\
\hline & $1 \mu \mathrm{M}$ & 240 & 5 & $37.5 \pm 12.53 \%^{*}$ & $52.9 \pm 7.84 \% *$ & $57.7 \pm 11.56 \% *$ \\
\hline & $5 \mu \mathrm{M}$ & 240 & 5 & 0 & $X$ & $x$ \\
\hline \multirow[t]{3}{*}{ Mib } & $0.5 \mu \mathrm{M}$ & 240 & 5 & $77.3 \pm 5.74 \%$ & $55.6 \pm 10.60 \%$ & $67.5 \pm 8.82 \%$ \\
\hline & $5 \mu \mathrm{M}$ & 240 & 5 & $36.7 \pm 5.68 \% *$ & $42.5 \pm 5.93 \% \%^{*}$ & $66.4 \pm 10.34 \%$ \\
\hline & $10 \mu \mathrm{M}$ & 240 & 5 & $3.6 \pm 2.40 \% *$ & 0 & $x$ \\
\hline \multirow[t]{3}{*}{ GSK-7975 } & $10 \mu \mathrm{M}$ & 240 & 5 & $95.4 \pm 3.21 \%$ & $84.5 \pm 6.34 \%$ & $82.7 \pm 7.26 \%$ \\
\hline & $100 \mu \mathrm{M}$ & 240 & 5 & $83.8 \pm 5.21 \%$ & $82.6 \pm 5.83 \%$ & $58.4 \pm 11.57 \%$ \\
\hline & $1 \mathrm{mM}$ & 240 & 5 & $63.5 \pm 7.95 \% *$ & 0 & $x$ \\
\hline
\end{tabular}

Note:Tha indicates SERCAs inhibitor Thapsigargin. NS-8593 is a TRPM7 specific inhibitor. Mib indicates T-type Ca ${ }^{2+}$ channels inhibitor Mibefradil. GSK-7975A is an Orai1 specific inhibitor. PA indicates survival embryos of all activated oocytes after activation. PN indicates pronuclear embryos from surviving oocytes. 2-Cell indicates cleaved embryos in pronuclear fertilized eggs. " $\mathrm{X}$ " indicates none available data. The significance of differences between Inhibitors and Ctrl group were analyzed by the Chi-square test and $p<0.05(*)$ was considered statistically significant 
$5 \mu \mathrm{M}$. The oocyte survival rate was $37.5 \%$ when treating with $1 \mu \mathrm{M}$ NS-8593. When treating with $5 \mu \mathrm{M}$ NS-8593, all oocytes died in a short time. Mibefradil was added with gradient concentrations of $0.5,5$, and $10 \mu \mathrm{M}$. Under $10 \mu \mathrm{M}$, activation of most oocytes was blocked. When applying GSK-7975A, an Orailblocker, with gradient concentrations of $10,100 \mu \mathrm{M}$, and $1 \mathrm{mM}$, oocytes were still activated at concentrations of $10 \mu \mathrm{M}$ and $100 \mu \mathrm{M}$ GSK-7975A. Pronuclear formation was suppressed significantly when GSK-7975A reached $1 \mathrm{mM}$, but this concentration had severe cytotoxicity. We found that SERCAs, TRPM7 and T-type $\mathrm{Ca}^{2+}$ channels played an important role in activation, while inhibition of Orail did not affect oocyte activation. In our subsequent experiments, we selected a moderate concentration of inhibitors to observe the effect of $\left[\mathrm{Ca}^{2+}\right]_{\mathrm{i}}$ oscillations on mitochondrial dynamic potential.

\section{Dynamic changes in $\left[\mathrm{Ca}^{2+}\right]_{i}$ and mitochondrial potential during oocyte activation}

Cytoplasmic $\mathrm{Ca}^{2+}$ concentration $\left(\left[\mathrm{Ca}^{2+}\right]_{\mathrm{i}}\right)$ oscillations and mitochondrial dynamic potential changes during the activation of oocytes were observed by time-lapse confocal laser microscope (UltraVIEW-VoX, PerkinElmer, Massachusetts, USA). Normal $\left[\mathrm{Ca}^{2+}\right]_{i}$ oscillations were induced by $\mathrm{SrCl}_{2}$ stimulation (Fig. 1a). We found that mitochondria were activated from the cortex to the internal area of the oocyte and finally aggregated around the chromosomes (Fig. 1b). In order to analyze changes in oocyte mitochondrial membrane potential, a relative fluorescence intensity analysis and a high membrane potential/low membrane potential ratio were introduced. Ordinate was marked as Relative Fluorescence Intensity (relative to the fluorescence intensity of the start point). The overall membrane potential showed two elevated peaks and then returned to a basal level (Fig. 1c, d). Oocyte cytoskeleton (spindle in Fig. 1e, and f-actin in Fig. 1f) showed a clear dynamic distribution during activation.

\section{Effect of SERCAs inhibitor Thapsigargin on oocyte activation}

Endoplasmic reticulum (ER) is a major $\mathrm{Ca}^{2+}$ storage component in the cytoplasm. SERCAs are the main transporters for cytoplasmic $\mathrm{Ca}^{2+}$ refilling into the ER. We wanted to observe changes in $\left[\mathrm{Ca}^{2+}\right]_{\mathrm{i}}$ oscillations and mitochondrial activity during oocyte activation after the $\mathrm{Ca}^{2+}$ refill was blocked by SERCAs inhibitor Thapsigargin (Tha) (Fig. 2). The oocyte survival rate was $66.2 \%$ when treating with $1 \mu \mathrm{M}$ Tha (Table. 1 ), by which concentration $\left[\mathrm{Ca}^{2+}\right]_{i}$ oscillations (Fig. 2a) and pronuclear formation were sufficiently suppressed. Mitochondrial membrane potential continued to decrease under $\mathrm{Ca}^{2+}$ refilling inhibition by $1 \mu \mathrm{M}$ Tha (Fig. 2b). At a concentration of $10 \mu \mathrm{M}$ Tha completely inhibited $\mathrm{Ca}^{2+}$ refill into ER, and oocyte died during activation (Fig. 2a). Ordinate was marked as Relative Fluorescence Intensity (relative to the fluorescence intensity of the start point). Spindle (Fig. 2d) and F-actin (Fig. 2e) showed dispersion when $1 \mu \mathrm{M}$ Tha caused oocyte death. Thus, $\mathrm{Ca}^{2+}$ refilling into ER through SERCAs plays an important role in $\left[\mathrm{Ca}^{2+}\right]_{\mathrm{i}}$ oscillations and mitochondrial activation during oocyte activation.

\section{Effect of TRPM7 inhibitor NS-8593 on oocyte activation}

TRPM7 is highly expressed in the GV and MII oocytes, mainly distributed on the plasma membrane. We inhibited TRPM7 activity by its specific inhibitor NS-8593 to study its role in oocyte activation (Fig. 3). The $\left[\mathrm{Ca}^{2+}\right]_{\mathrm{i}}$ oscillations (Fig. 3a) and pronuclear formation were sufficiently suppressed when $1 \mu \mathrm{M}$ NS-8593 was used to inhibit the transport of $\mathrm{Ca}^{2+}$ through TRPM7. The dynamic mitochondrial membrane potential of oocytes was observed after treatment with $1 \mu \mathrm{M}$ NS-8593 (Fig. 3b). At this concentration, mitochondrial membrane potential continuously decreased. Depolarization of mitochondria was found in the case of long-term inhibition (Fig. 3b). When treating with $5 \mu \mathrm{M}$ NS-8593, $\left[\mathrm{Ca}^{2+}\right]_{i}$ slowly rose and finally induced oocyte death. Ordinate was marked as Relative Fluorescence Intensity (relative to the fluorescence intensity of the start point). Spindle (Fig. 3d) and F-actin (Fig. 3e) showed dispersion when $1 \mu \mathrm{M}$ NS-8593 caused oocyte death. Thus, $\left[\mathrm{Ca}^{2+}\right]_{\mathrm{i}}$ oscillations regulated through TRPM7 are important for mitochondrial activity during oocyte activation.

\section{Effect of T-type $\mathrm{Ca}^{2+}$ channel inhibitor Mibefradil on oocyte activation}

T-type $\mathrm{Ca}^{2+}$ channels including Cav3.1, Cav3.2, and Cav3.3 subtypes are distributed on the plasma membrane. Mibefradil can suppress all three T-type $\mathrm{Ca}^{2+}$ channels. Mibefradil was introduced to study the role of T-type $\mathrm{Ca}^{2+}$ channels in $\left[\mathrm{Ca}^{2+}\right]_{\mathrm{i}}$ oscillations (Fig. 4). The mitochondrial membrane potential was observed in the $5 \mu \mathrm{M}$ group. We found that the mitochondrial membrane potential continued to decrease after inhibiting the transport of $\mathrm{Ca}^{2+}$ through T-type $\mathrm{Ca}^{2+}$ channels. When the concentration was increased to $10 \mu \mathrm{M}$, $\mathrm{Ca}^{2+}$ slowly increased, which induced rapid death of most oocytes. Ordinate was marked as Relative Fluorescence Intensity (relative to the fluorescence intensity of the start point). Spindle (Fig. 3d) and F-actin (Fig. 3e) showed dispersion when $5 \mu \mathrm{M}$ Mibefradil caused oocyte death. Based on these results it is concluded that the transport of $\mathrm{Ca}^{2+}$ through T-type $\mathrm{Ca}^{2+}$ channels is important for $\left[\mathrm{Ca}^{2+}\right]_{\mathrm{i}}$ oscillations and mitochondrial activity in oocyte activation and survival. 


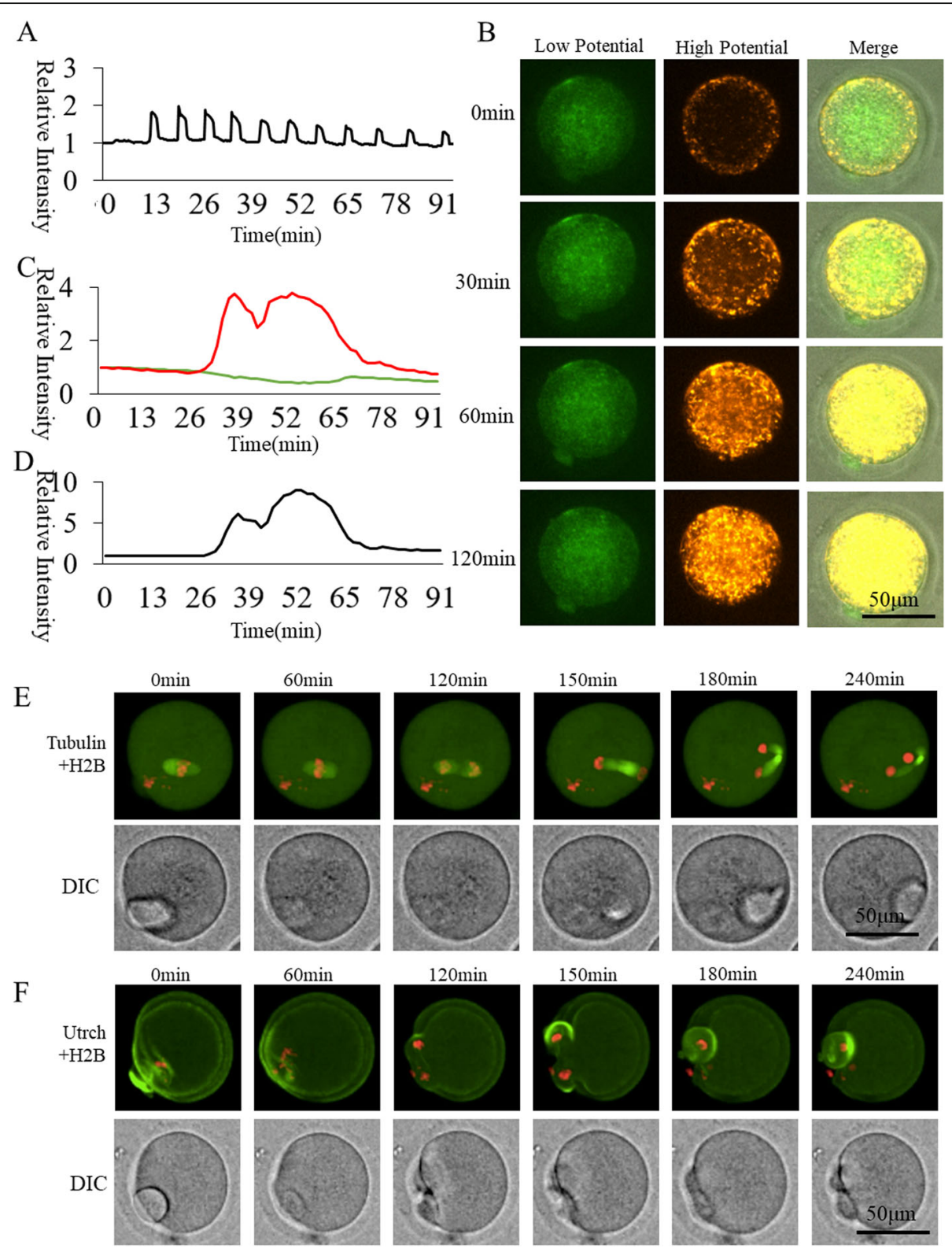

Fig. $1\left[\mathrm{Ca}^{2+}\right]$ i and mitochondrial membrane potential of wildtype activated oocytes. a Cytoplasmic calcium concentrations ([Ca $\left.\left.{ }^{2+}\right]_{\mathrm{i}}\right)$ showing dynamic changes in wildtype oocytes during activation. b Oocyte mitochondrial membrane potential of wildtype oocytes during activation. $\mathbf{c}$ Membrane potential fluorescence intensity during oocyte activation. The green and red curves represent labeling with JC-1, indicating relative fluorescence intensities of low membrane potential (488 nm excitation, $525 \mathrm{~nm}$ emission) and high membrane potential (561 excitation, 590 emission), respectively. d The black curve shows the ratio of high membrane potential to low membrane potential indicating relative mitochondrial membrane potential. e Living cell observation of Ctrl oocyte spindle formation $\mathbf{f}$ Living cell observation of subcortical F-actin distribution in Ctrl oocyte

Effect of Orai1 inhibitor GSK-7975A on oocyte activation Orail is distributed on the plasma membrane. We studied the role of Orai1 in oocyte activation by treating oocytes with the specific inhibitor GSK-7975A. The mitochondrial membrane potential was observed at $1 \mathrm{mM}$, which showed irregular changes compared to the Ctrl group (Fig. 5). Most oocytes survived until $4 \mathrm{~h}$ of activation, but none of them formed a pronucleus due to cytotoxicity. Ordinate was marked as Relative Fluorescence Intensity (relative to the fluorescence intensity of the start point). It was not confirmed whether this $\left[\mathrm{Ca}^{2+}\right]_{\mathrm{i}}$ oscillation pattern and mitochondria membrane potential changes were caused by complete inhibition of Orail or by cytotoxicity induced by the high concentration of $1 \mathrm{mM}$ GSK-7975A. Oocytes spindle (Fig. 3d) showed a chromosome segregation and F-actin false distribution when $1 \mathrm{mM}$ GSK-7975A caused oocyte fragmentation. The role of Orail in the activation of oocytes requires additional evidence to confirm. 


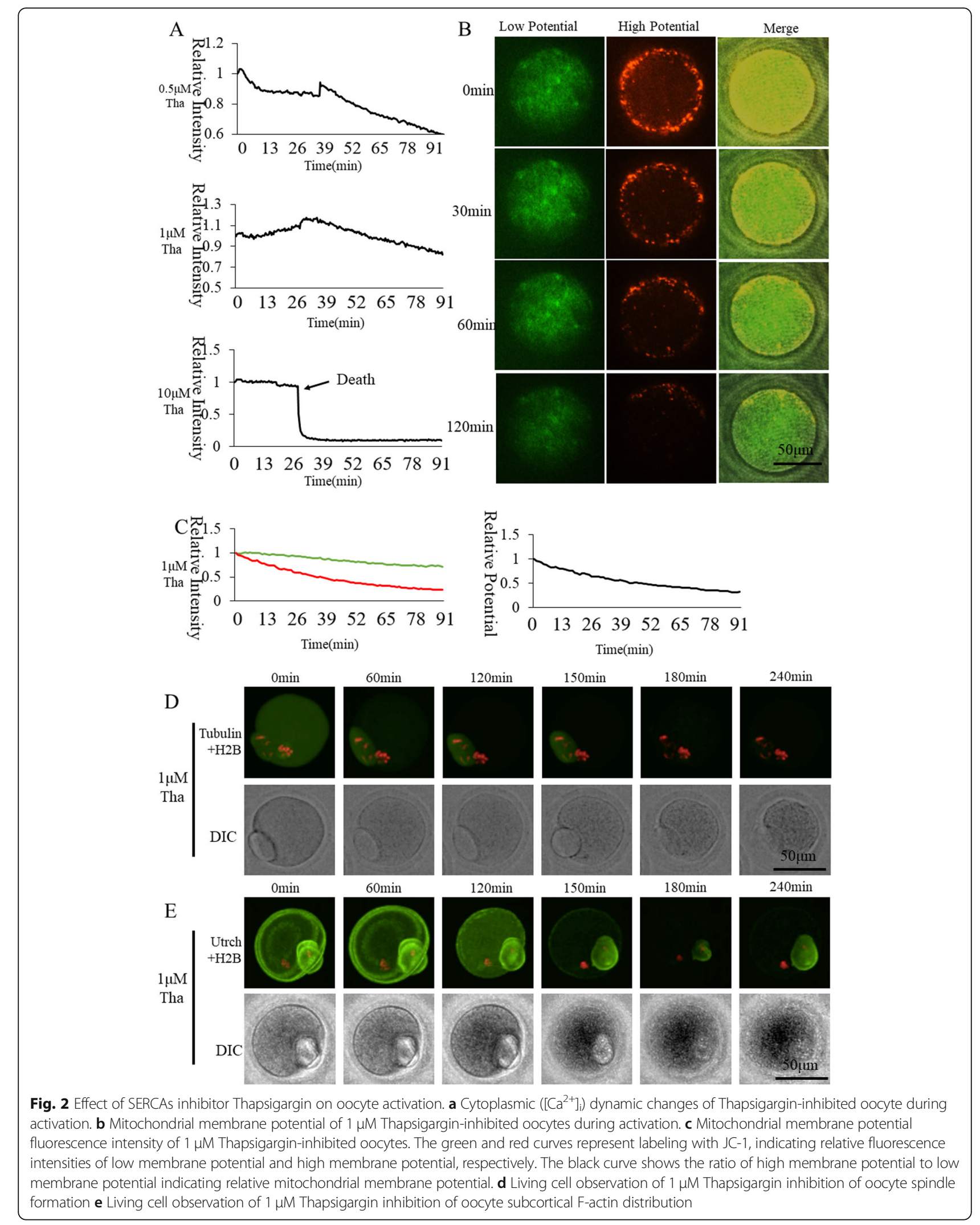




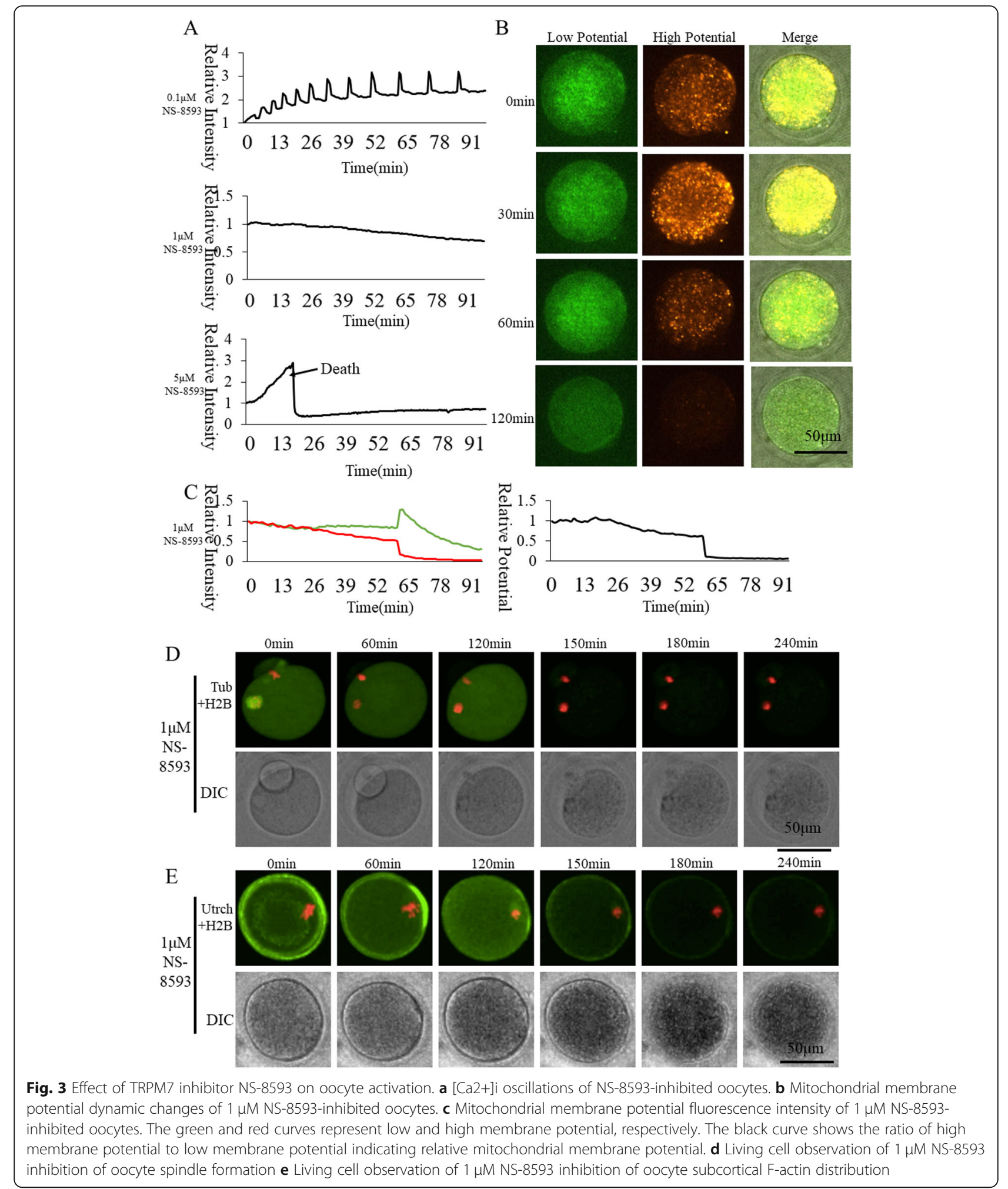

Effects of $\mathrm{Ca}^{2+}$ channel inhibitors on long-lasting $\left[\mathrm{Ca}^{2+}\right]_{\mathrm{i}}$ oscillations

The mechanisms of initiation and maintenance of $\left[\mathrm{Ca}^{2+}\right]_{\mathrm{i}}$ oscillations are believed to be different. However, it is unclear which transporters participate in the initiation or maintenance. The effects of several transporters on the maintenance of $\left[\mathrm{Ca}^{2+}\right]_{\mathrm{i}}$ oscillations were investigated in our study (Fig. 6). By using time-lapse confocal 


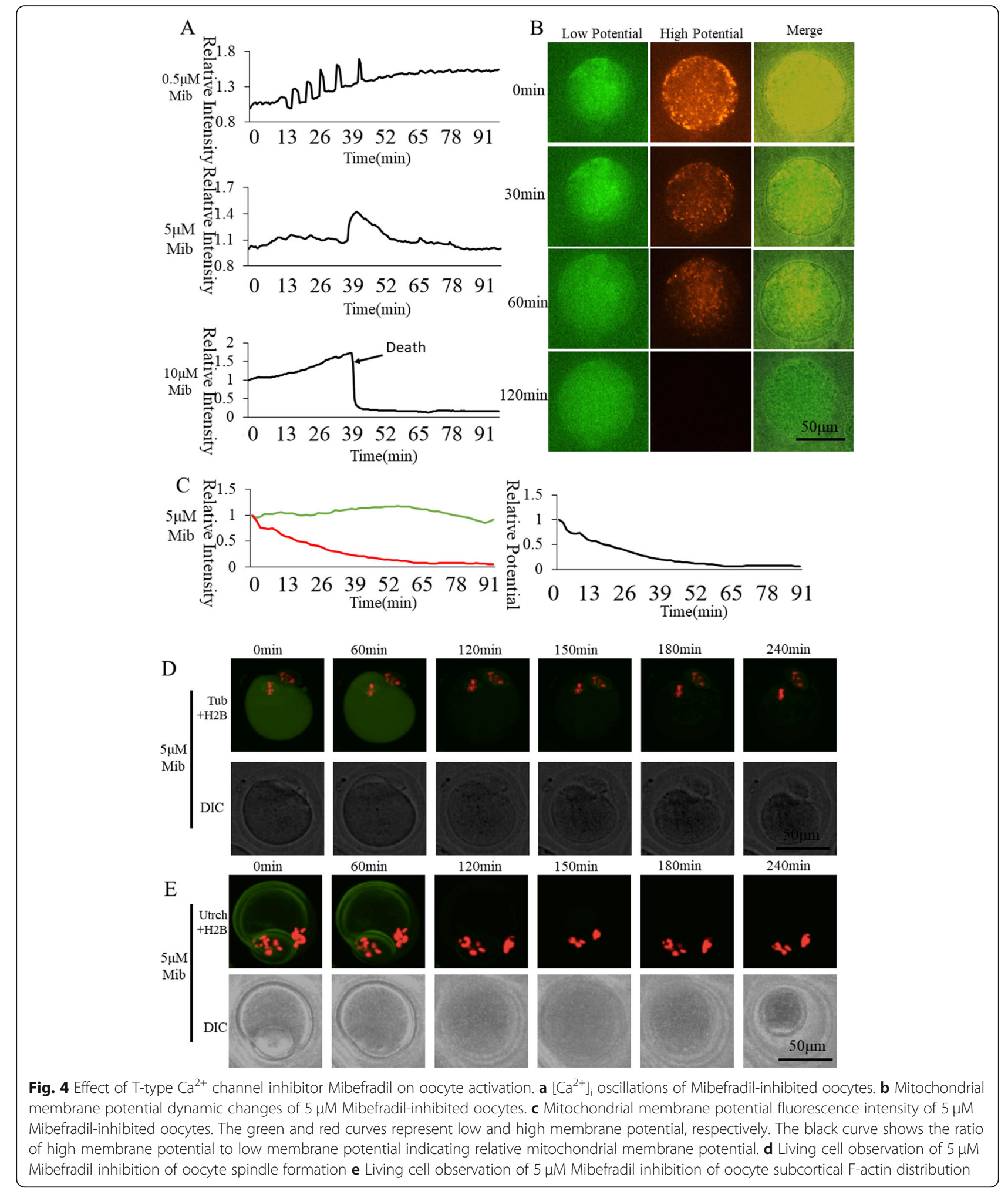

laser microscope we observed the effect of various inhibitors on the maintenance of $\left[\mathrm{Ca}^{2+}\right]_{\mathrm{i}}$ oscillations after some initial oscillations (Fig. 6a). The same concentration was applied as in the mitochondrial membrane potential observation study mentioned above. Ruthenium Red (MACKLIN, Beijing, China) completely inhibited oocyte activation as a non-specific cation channel inhibitor. It was found that the addition of Ruthenium 

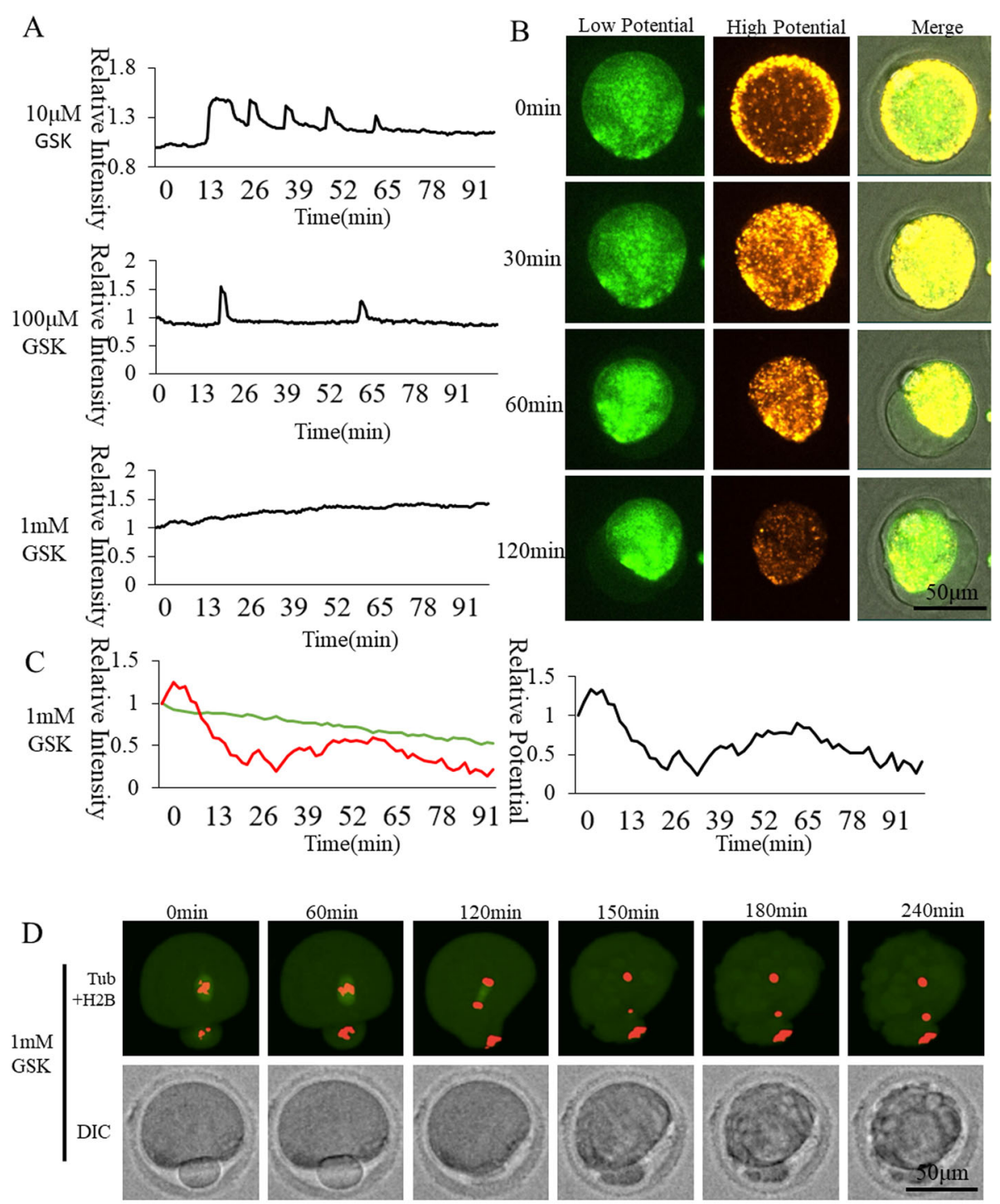

$240 \mathrm{~min}$
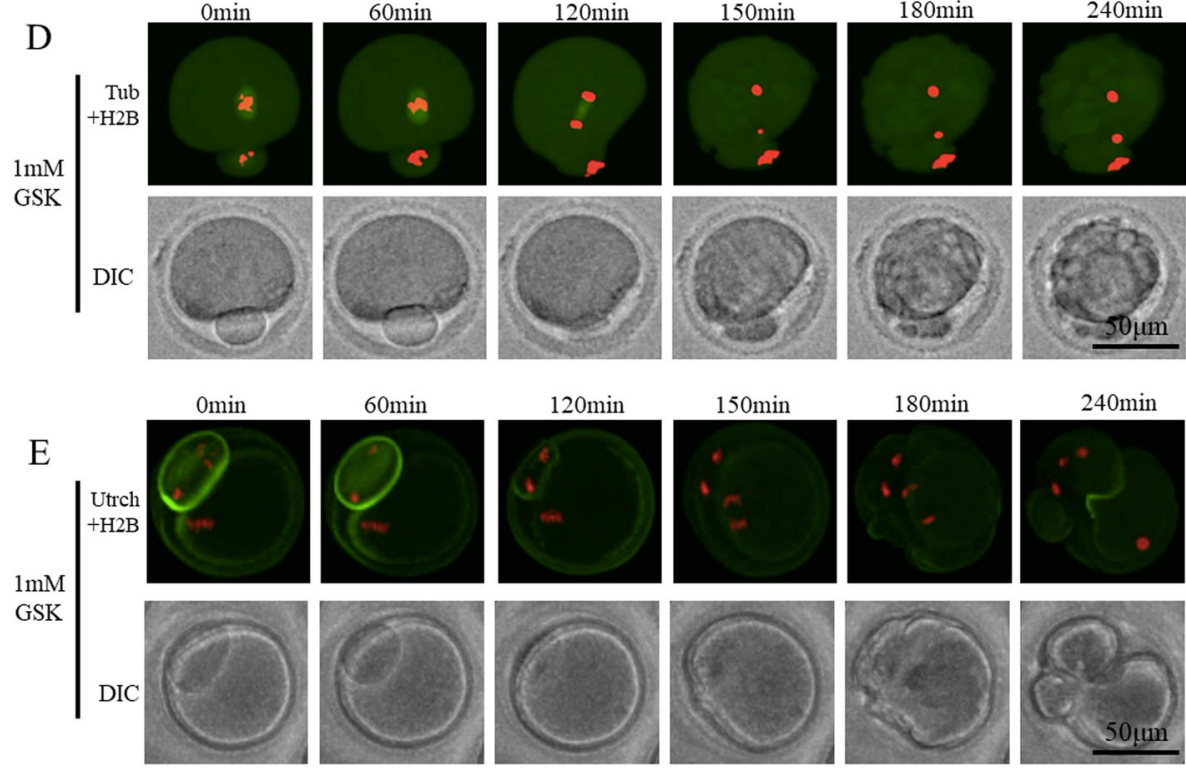

Fig. 5 Effect of Orai1 inhibitor GSK-7975A on oocyte activation. a $\left[\mathrm{Ca}^{2+}\right]_{i}$ oscillations of GSK-7975A-inhibited oocytes. b Mitochondrial membrane potential dynamic changes of 1 mM GSK-7975A-inhibited oocytes. c Mitochondrial membrane potential fluorescence intensity of 1 mM GSK-7975Ainhibited oocytes. The green and red curves represent low and high membrane potential, respectively. The black curve shows the ratio of high membrane potential to low membrane potential indicating relative mitochondrial membrane potential. $\mathbf{d}$ Living cell observation of 1 mM GSK-7975A inhibition of oocyte spindle formation e Living cell observation of 1 mM GSK-7975A inhibition of oocyte subcortical F-actin distribution

Red, Thapsigargin or GSK-7975A inhibited $\mathrm{Ca}^{2+}$ transport, and the $\left[\mathrm{Ca}^{2+}\right]_{\mathrm{i}}$ oscillations were blocked from the time of inhibitor addition. After addition of Mibefradil or NS-8593, the intracellular $\mathrm{Ca}^{2+}$ increased continuously, and the cell death rate was higher than in the Ctrl and other groups. Based on these results it is concluded 


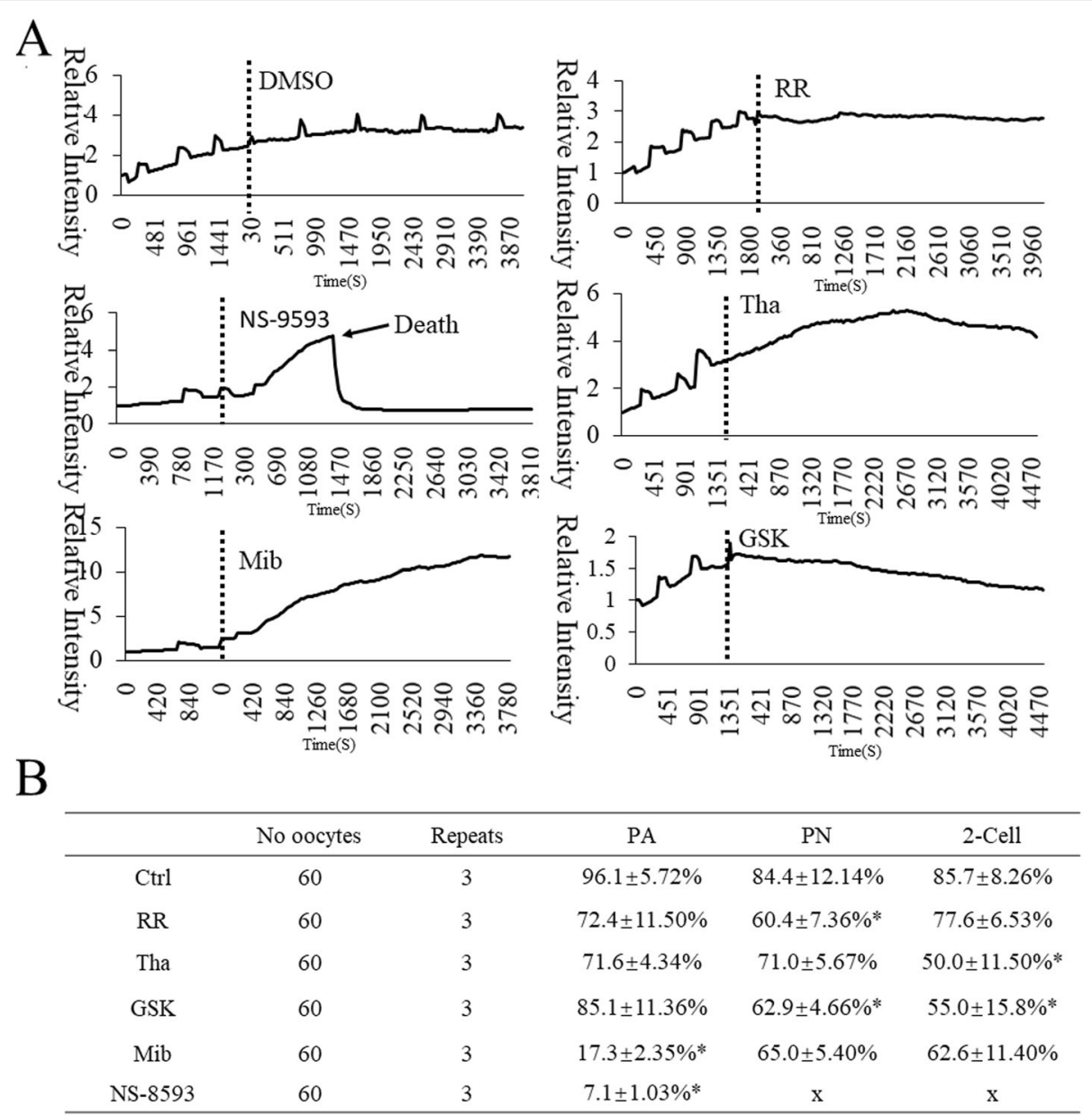

Fig. 6 Inhibitor effects on on long-lasting $\left[\mathrm{Ca}^{2+}\right]_{i}$ oscillations. a Cytoplasmic $\left[\mathrm{Ca}^{2+}\right]_{i}$ dynamic changes after inhibitor addition. b Development of inhibitor addition following $\left[\mathrm{Ca}^{2+}\right]_{i}$ oscillations initiation. PA indicates survival of embryos of all Mll oocytes. PN indicates pronuclear embryos of surviving oocytes. 2-Cell indicates cleaved embryos of pronuclear embryos. RR: $10 \mu$ M Ruthenium Red; Tha: 1 MM Thapsigargin; GSK: 1 mM GSK7975A; Mib: Mibefradil; N: 1 MM NS-8593. The significance of differences between groups was analyzed by the Chi-square test and $p<0.05\left(^{*}\right)$ was considered statistically significant. $(X)$ indicates data unavailable

that the three $\mathrm{Ca}^{2+}$ transporters, SERCAs, TRPM7 and T-type $\mathrm{Ca}^{2+}$ channels, are not only involved in $\left[\mathrm{Ca}^{2+}\right]_{\mathrm{i}}$ oscillation initiation but also in $\left[\mathrm{Ca}^{2+}\right]_{\mathrm{i}}$ oscillations maintenance. Interestingly, the effect of Ruthenium Red and other inhibitors added into culture of oocytes which had already initiated $\left[\mathrm{Ca}^{2+}\right]_{\mathrm{i}}$ oscillations in oocytes did not significantly influence oocyte activation (Fig. 6b), suggesting that oocyte activation and pronuclear formation require only a small amount of $\left[\mathrm{Ca}^{2+}\right]_{\mathrm{i}}$ oscillations. The function of long-lasting $\left[\mathrm{Ca}^{2+}\right]_{\mathrm{i}}$ oscillations in embryo development requires further study.

\section{Discussion}

Obese, diabetic and aging women typically suffer from abnormal body metabolism such as hypertension, hyperglycemia and hyperlipidemia [19-24], causing long-term stress in oocytes [25], which severely damages the quality of oocytes, thereby leading to lower pregnancy rates
[26]. Insufficient oocyte activation and mitochondrial damage were considered to be major causes for embryo developmental disorders [27, 28].

$\mathrm{Ca}^{2+}$ is one of the major signal molecules that regulate various cell functions including cell cycle progression, arrest and apoptosis. Oocyte activation induces a continuous series of oocyte intracellular $\mathrm{Ca}^{2+}$ concentration $\left(\left[\mathrm{Ca}^{2+}\right]_{\mathrm{i}}\right)$ increases and decreases known as $\left[\mathrm{Ca}^{2+}\right]_{\mathrm{i}}$ oscillations, which encode oocyte activation events, including release from the MII arrest, pronuclear formation and the transition to embryo development [29]. Release of $\mathrm{Ca}^{2+}$ from internal stores and $\mathrm{Ca}^{2+}$ influx from the extracellular matrix induce moderate increases in $\left[\mathrm{Ca}^{2+}\right]_{\mathrm{i}}$ levels. The increase in $\left[\mathrm{Ca}^{2+}\right]_{\mathrm{i}}$ generally lasts about 2 min. As $\mathrm{Ca}^{2+}$ refills back into the ER or causes efflux from the cytoplasm to prepare for the next peak of oscillation, the elevated $\left[\mathrm{Ca}^{2+}\right]_{\mathrm{i}}$ will return to baseline levels, resulting in an average of a ten to twenty minutes 
resting interval. $\left[\mathrm{Ca}^{2+}\right]_{\mathrm{i}}$ oscillations will last $5-6 \mathrm{~h}$ until pronuclear formation takes place [9]. The repeated elevation and recovery of $\mathrm{Ca}^{2+}$ signaling is tightly regulated, and the strictly ordered $\mathrm{Ca}^{2+}$ signal will coordinate the interaction of various organelles in the oocyte for its activation. $\mathrm{Ca}^{2+}$ transporters and regulators could become potential therapy targets for in vitro fertilization failure.

During cell activation, $\mathrm{Ca}^{2+}$ shuttles through the cell, and the transporter is likely to be located near IP3R and downstream organelles [30]; the cell membrane, lysosomes, the nucleus, vesicles and mitochondria may be targets of $\mathrm{Ca}^{2+}$ release. Endoplasmic reticulum (ER) is a main intracellular $\mathrm{Ca}^{2+}$ store, where the $\mathrm{Ca}^{2+}$ concentration increases to 300 or even $1000 \mu \mathrm{M}$ [31]. The pathway for $\mathrm{Ca}^{2+}$ efflux from the ER into the cytoplasm has not yet been well identified. SOCE or $\mathrm{Ca}^{2+}$ releaseactivated $\mathrm{Ca}^{2+}$ channels (CRAC), were first described in immune cells where they have been shown to be critical for their function. Accordingly, defects in SOCE in humans are associated with severe immune-deficiencies [32]. In oocytes, the predominant $\left[\mathrm{Ca}^{2+}\right]_{\mathrm{i}}$ increase pathway appears to be achieved through store-operated $\mathrm{Ca}^{2+}$ entry (SOCE) processes. $\mathrm{Ca}^{2+}$ enters the cytosol from the endoplasmic reticulum (ER), which in turn opens one of the ER channels, sarcoplasmic reticulum/ER CaATPase (SERCAs), to transport $\mathrm{Ca}^{2+}$ back to the ER [33]. Total cellular $\mathrm{Ca}^{2+}$ was estimated by the addition of $10 \mu \mathrm{M}$ Thapsigargin (Tha), a SERCAs inhibitor, which induced complete release of $\mathrm{Ca}^{2+}$ from ER [34]. When ER $\mathrm{Ca}^{2+}$ stores had been significantly depleted by Tha, sperm no longer triggered $\left[\mathrm{Ca}^{2+}\right]_{i}$ oscillations [35]. In our study, we used three gradient concentrations of 0.5 , 1 and $10 \mu \mathrm{M}$ of Tha. Ten $\mu \mathrm{M}$ Tha kept oocytes at a higher $\left[\mathrm{Ca}^{2+}\right]_{\mathrm{i}}$ and all oocytes died before the end of the activation process (Fig. 2). However, when oocyte $\left[\mathrm{Ca}^{2+}\right]_{i}$ oscillations were suppressed by $1 \mu \mathrm{M}$ Tha, more than half of the oocytes survived more than $4 \mathrm{~h}$. Under such moderate concentration, the effects of SERCAs on mitochondrial activity can be observed for a long term. Oocyte mitochondrial membrane potential continued to decrease under $\mathrm{Ca}^{2+}$ refilling inhibition with $1 \mu \mathrm{M}$ Tha incubation. Not only $\left[\mathrm{Ca}^{2+}\right]_{\mathrm{i}}$ oscillations but also mitochondrial activity were suppressed by Tha that induced blocking of $\mathrm{ER} \mathrm{Ca}^{2+}$ refilling. Finally, oocytes cannot be activated under SERCAs inhibition.

Recently, a member of the TRP channels family, TRPM7, was found to be expressed in mouse GV, MII oocytes and 2-cell embryos [36]. TRPM7 belongs to the subfamily of melastatin and exhibits a ubiquitous tissue distribution. Trpm7 knock-out caused E14.5 embryonic lethality [37]. Using inhibitor NS-8593 suppression of the transporter hours after activation reduced progression to the blastocyst stage [36]. Oocytes treated with $10 \mu \mathrm{M}$ NS-8593 and fertilized in vitro display impaired
$\mathrm{Ca}^{2+}$ oscillations [15]. We applied NS-8593 with gradient concentrations of $0.1,1$, and $5 \mu \mathrm{M}$ (Tab. 1 and Fig. 3a). After treating with $5 \mu \mathrm{M}$ NS-8593, $\left[\mathrm{Ca}^{2+}\right]_{\mathrm{i}}$ slowly rose, which finally induced oocyte death. Treatment with $1 \mu \mathrm{M}$ NS-8593 kept the survival rate at $37.5 \%$ (Fig. 3), while the $\left[\mathrm{Ca}^{2+}\right]_{\mathrm{i}}$ oscillations and pronuclear formation were sufficiently suppressed. Under this moderate concentration of $1 \mu \mathrm{M}$ NS-8593, the effects of TRPM7 on mitochondrial activity can be observed for a long time. Mitochondrial activity did not exhibit the same activation state as the Ctrl in the case of TRPM7 inhibition with NS-8593. Mitochondrial membrane potential continuously decreased when inhibiting the transport of $\mathrm{Ca}^{2+}$ through TRPM7 with $1 \mu \mathrm{M}$ NS-8593 (Fig. 3). The TRPM7 on the cell membrane of oocytes has a significant effect on the $\left[\mathrm{Ca}^{2+}\right]_{\mathrm{i}}$ oscillation patterns in oocytes, and $\left[\mathrm{Ca}^{2+}\right]_{\mathrm{i}}$ oscillations achieved through TRPM7 is important for mitochondrial activity and oocyte activation.

Mibefradil is a T-type channel inhibitor. Mibefradil was developed as a cardiovascular hypertension and angina remedy [38]. Mibefradil has been repurposed as an anti-cancer drug [39]. However, its underlying mechanisms are still unclear. The mechanism of the anticancer therapy is thought to be via the blockage of $\mathrm{Ca}^{2+}$ influx through T-type channels [40]. Mibefradil blocks all three subtypes of T-type channels [41], including Cav3.1, Cav3.2, and Cav3.3, with an IC50 (semi-lethal concentration) of 5.8-7.2 $\mu \mathrm{M}$. In our study, inhibition of $\mathrm{Ca}^{2+}$ release by high concentrations of Mibefradil impaired intracellular $\mathrm{Ca}^{2+}$ dynamics and thus affected cell viability. We applied Mibefradil at three gradient concentrations of $0.5,5$, and $10 \mu \mathrm{M}$ (Tab. 1 and Fig. 4). In order to conduct long term observations, a moderate concentration of $5 \mu \mathrm{M}$ NS-8593 was selected to study the effects of T-type channels on mitochondrial activity. The mitochondrial membrane potential continued to decrease after inhibiting the transport of $\mathrm{Ca}^{2+}$ through T-type $\mathrm{Ca}^{2+}$ channels with $5 \mu \mathrm{M}$ Mibefradil. When the concentration reached $10 \mu \mathrm{M}, \mathrm{Ca}^{2+}$ rapidly increased, which induced rapid death of most oocytes. Thus, transport of $\mathrm{Ca}^{2+}$ through T-type $\mathrm{Ca}^{2+}$ channels is important for mitochondrial activity and oocyte activation.

Orais represents transmembrane proteins that form highly $\mathrm{Ca}^{2+}$-selective channels [42]. Orais has three family members, ORAI1, 2 and 3 [43]. Loss-of-function mutation of ORAI1 caused immune deficiency [44] and dysfunction of thrombus formation [45]. SOCE is also mediated through the ORAI channels at the outer membrane. $10 \mu \mathrm{M}$ GSK-7975A has been reported to induce maximal inhibition of $\mathrm{Ca}^{2+}$ influx in Jurkat T-cells [17]. We applied GSK-7975A at gradient concentrations of $10,100 \mu \mathrm{M}$, and $1 \mathrm{mM}$. We found that oocytes could not be activated when GSK-7975A below $1 \mathrm{mM}$ was used to effectively inhibit $\mathrm{Ca}^{2+}$ influx. Mitochondrial 
dynamic membrane potential showed irregular changes compared to the Ctrl group (Fig. 5). Most of the oocytes survived up to $4 \mathrm{~h}$ post activation even at a concentration as high as $1 \mathrm{mM}$, but none of them formed a pronucleus. Female mice were fertile after knocking out ORAI1 [15]. It is not yet clear whether this $\left[\mathrm{Ca}^{2+}\right]_{\mathrm{i}}$ oscillation pattern and membrane potential changes were caused by complete inhibition of Orail or by cytotoxicity induced by the high concentration of $1 \mathrm{mM}$. The role of Orail in the activation of oocytes requires additional evidence to confirm.

The mechanisms of initiation and maintenance of $\left[\mathrm{Ca}^{2+}\right]_{\mathrm{i}}$ oscillations are different [46]. However, it is unclear which transporters participate in the initiation or maintenance of $\left[\mathrm{Ca}^{2+}\right]_{i}$ oscillations. The effects of several transporters on the maintenance of $\left[\mathrm{Ca}^{2+}\right]_{\mathrm{i}}$ oscillations were investigated in our study (Fig. 6). We found that the addition of Ruthenium Red, Thapsigargin and GSK$7975 \mathrm{~A}$ all inhibited the maintenance of $\left[\mathrm{Ca}^{2+}\right]_{\mathrm{i}}$ oscillations. After addition of Mibefradil and NS-8593, the intracellular $\mathrm{Ca}^{2+}$ increased continuously, and the cell death rate was higher than in the Ctrl and other groups. All these results suggest that three $\mathrm{Ca}^{2+}$ transporters, SERCAs, TRPM7 and T-type $\mathrm{Ca}^{2+}$ channels are involved in both the initiation and maintenance of $\left[\mathrm{Ca}^{2+}\right]_{i}$ oscillations. Interestingly, the addition of Ruthenium Red and other inhibitors into culture of oocytes which had initiated $\left[\mathrm{Ca}^{2+}\right]_{\mathrm{i}}$ oscillations did not significantly influence oocyte activation (Fig. 6b), suggesting that oocyte activation required only a small amount of $\left[\mathrm{Ca}^{2+}\right]_{\mathrm{i}}$ oscillations.

In summary, we applied ER-associated $\mathrm{Ca}^{2+}$ transporter SERCAs inhibitor Thapsigargin, TRPM7 inhibitor NS-8593, T-type $\mathrm{Ca}^{2+}$ channels inhibitor Mibefradil, and Orai1 inhibitor GSK-7975A to understand the regulation of $\left[\mathrm{Ca}^{2+}\right]_{\mathrm{i}}$ oscillations and mitochondrial activity during oocyte activation, and showed that inhibition of SERC As, TRPM7 and T-type $\mathrm{Ca}^{2+}$ channels caused disturbances in $\mathrm{Ca}^{2+}$ signaling, mitochondrial activity and subsequent oocyte activation and embryonic development. Once $\mathrm{Ca}^{2+}$ transport is abnormal in oocytes, whether it is at the beginning or halfway, will cause disorders of mitochondrial metabolism, activation of subsequent developmental consequences, finally leading to infertility.

\section{Abbreviations}

GV: Germinal Vesicle; GVBD: Germinal Vesicle Breakdown; MII: Metaphase II: $\left[\mathrm{Ca}^{2+}\right]_{i}$ : Intracellular $\mathrm{Ca}^{2+}$ Concentration; $\left[\mathrm{Ca}^{2+}\right]_{\mathrm{m}}$ : Mitochondrial Matrix $\mathrm{Ca}^{2+}$ Concentration; SERCAs: Sarcoplasmic/endoplasmic reticulum $\mathrm{Ca}^{2+}$ ATPases; TRPM7: Transient receptor potential (TRP) ion channel subfamily member 7; ER: Endoplasmic reticulum; ART: Assisted reproductive technologies

\section{Acknowledgements}

Not applicable.

\section{Authors' contributions}

Feng Wang, Qing-Yuan Sun and Xiang-Hong Ou conceived and designed the experiments. Feng Wang and others conducted experiments. Feng Wang and Qing-Yuan Sun analyzed the data. Feng Wang, Heide Schatten, QingYuan Sun and Xiang-Hong Ou wrote the manuscript. The author(s) read and approved the final manuscript.

\section{Funding}

This work was sponsored by National Natural Science Foundation of China (81971357; 81901477) and Science Foundation of Guangdong Second Provincial General Hospital, Grant/Award Number: YN-2018-004.

\section{Availability of data and materials}

Some or all data used during the study are available from the corresponding author by request.

\section{Consent for publication}

The manuscript is approved by all authors for publication, and it is original research that has not been published previously, and is not being submitted to any other journal in whole or in part.

\section{Competing interests}

I would like to state that there is no conflict of interest or financial disclosure to declare for this manuscript.

\section{Author details}

${ }^{1}$ Fertility Preservation Lab, Reproductive Medicine Center, Guangdong Second Provincial General Hospital, Guangzhou 510317, China. ${ }^{2}$ China State Key Laboratory of Stem Cell and Reproductive Biology, Institute of Zoology, Chinese Academy of Sciences, Beijing 100101, China. ${ }^{3}$ Department of Veterinary Pathobiology, University of Missouri, Columbia, MO 65211, USA.

Received: 15 April 2020 Accepted: 10 August 2020

Published online: 15 August 2020

\section{References}

1. Chow KM, Cheung MC, Cheung IK. Psychosocial interventions for infertile couples: a critical review. J Clin Nurs. 2016;25:2101-13.

2. Schatten $H$, Sun QY, Prather R. The impact of mitochondrial function/ dysfunction on IVF and new treatment possibilities for infertility. Reprod Biol Endocrinol. 2014;12:111.

3. Stricker SA. Comparative biology of calcium signaling during fertilization and egg activation in animals. Dev Biol. 1999;211:157-76.

4. Wakai $T$, Zhang N, Vangheluwe $P$, Fissore RA. Regulation of endoplasmic reticulum $\mathrm{Ca}(2+)$ oscillations in mammalian eggs. J Cell Sci. 2013;126:5714-24.

5. Yazawa H, Yanagida K, Sato A. Human round spermatids from azoospermic men exhibit oocyte-activation and Ca2+ oscillation-inducing activities. Zygote. 2007;15:337-46.

6. Carvacho I, Piesche M, Maier TJ, Machaca K. Ion Channel function during oocyte maturation and fertilization. Front Cell Dev Biol. 2018;6:63.

7. Marchi S, Patergnani S, Missiroli S, Morciano G, Rimessi A, Wieckowski MR, et al. Mitochondrial and endoplasmic reticulum calcium homeostasis and cell death. Cell Calcium. 2018;69:62-72.

8. Miao YL, Stein P, Jefferson WN, Padilla-Banks E, Williams CJ. Calcium influxmediated signaling is required for complete mouse egg activation. Proc Natl Acad Sci U S A. 2012;109:4169-74.

9. Wang F, Yuan RY, Li L, Meng TG, Fan LH, Jing Y, et al. Mitochondrial regulation of $[\mathrm{Ca}(2+)]$ i oscillations during cell cycle resumption of the second meiosis of oocyte. Cell Cycle. 2018;17(12):1471-86.

10. Shimizu H, Schredelseker J, Huang J, Lu K, Naghdi S, Lu F, et al. Mitochondrial $\mathrm{Ca}(2+)$ uptake by the voltage-dependent anion channel 2 regulates cardiac rhythmicity. Elife. 2015;4:e04801.

11. Burkel BM, von Dassow G, Bement WM. Versatile fluorescent probes for actin filaments based on the actin-binding domain of utrophin. Cell Motil Cytoskeleton. 2007;64:822-32.

12. Verlhac $M H$, Lefebvre $C$, Guillaud P, Rassinier P, Maro B. Asymmetric division in mouse oocytes: with or without Mos. Curr Biol. 2000;10:1303-6.

13. Yu XJ, Yi Z, Gao Z, Qin D, Zhai Y, Chen X, et al. The subcortical maternal complex controls symmetric division of mouse zygotes by regulating Factin dynamics. Nat Commun. 2014;5:4887.

14. Garcia-Perez C, Hajnoczky G, Csordas G. Physical coupling supports the local $\mathrm{Ca} 2+$ transfer between sarcoplasmic reticulum subdomains and the mitochondria in heart muscle. J Biol Chem. 2008;283:32771-80. 
15. Bernhardt ML, Padilla-Banks E, Stein P, Zhang Y, Williams CJ. Store-operated $\mathrm{Ca}(2+)$ entry is not required for fertilization-induced $\mathrm{Ca}(2+)$ signaling in mouse eggs. Cell Calcium. 2017;65:63-72.

16. Schafer S, Ferioli S, Hofmann T, Zierler S, Gudermann T, Chubanov V. Mibefradil represents a new class of benzimidazole TRPM7 channel agonists. Pflugers Arch. 2016:468:623-34.

17. Rice LV, Bax HJ, Russell L, Barrett VJ, Walton SE, Deakin AM, et al. Characterization of selective calcium-release activated calcium channel blockers in mast cells and T-cells from human, rat, mouse and Guinea-pig preparations. Eur J Pharmacol. 2013;704:49-57.

18. Stein P, Schindler K. Mouse oocyte microinjection, maturation and ploidy assessment. J Vis Exp. 2011;(53):2851. Published 2011 Jul 23.

19. Minge $C E$, Bennett $B D$, Norman RJ, Robker RL. Peroxisome proliferatoractivated receptor-gamma agonist rosiglitazone reverses the adverse effects of diet-induced obesity on oocyte quality. Endocrinology. 2008;149:2646-56.

20. Igosheva N, Abramov AY, Poston L, Eckert JJ, Fleming TP, Duchen MR, et al. Maternal diet-induced obesity alters mitochondrial activity and redox status in mouse oocytes and zygotes. PLoS One. 2010;5:e10074.

21. Jungheim ES, Schoeller EL, Marquard KL, Louden ED, Schaffer JE, Moley KH. Diet-induced obesity model: abnormal oocytes and persistent growth abnormalities in the offspring. Endocrinology. 2010:151:4039-46.

22. Wang F, Chen Z, Ren X, Tian Y, Liu C, Jin P, et al. Hormone-sensitive lipase deficiency alters gene expression and cholesterol content of mouse testis. Reproduction. 2017;153:175-85.

23. Shankar K, Zhong Y, Kang P, Lau F, Blackburn ML, Chen JR, et al. Maternal obesity promotes a proinflammatory signature in rat uterus and blastocyst. Endocrinology. 2011;152:4158-70.

24. Luzzo KM, Wang Q, Purcell SH, Chi M, Jimenez PT, Grindler N, et al. High fat diet induced developmental defects in the mouse: oocyte meiotic aneuploidy and fetal growth retardation/brain defects. PLoS One. 2012;7: e49217.

25. Wang F, Ren X-F, Chen Z, Li X-L, Zhu H-J, Li S, et al. The N-terminal his-tag affects the triglyceride lipase activity of hormone-sensitive lipase in testis. J Cell Biochem. J Cell Biochem. 2019;120(8):13706-16.

26. Jungheim ES, Schon SB, Schulte MB, DeUgarte DA, Fowler SA, Tuuli MG. IVF outcomes in obese donor oocyte recipients: a systematic review and metaanalysis. Hum Reprod. 2013;28:2720-7.

27. Gesink Law DC, Maclehose RF, Longnecker MP. Obesity and time to pregnancy. Hum Reprod. 2007;22:414-20.

28. Rittenberg V, Sobaleva S, Ahmad A, Oteng-Ntim E, Bolton V, Khalaf $Y$, et al. Influence of BMI on risk of miscarriage after single blastocyst transfer. Hum Reprod. 2011;26:2642-50.

29. Ducibella T, Huneau D, Angelichio E, Xu Z, Schultz RM, Kopf GS, et al. Eggto-embryo transition is driven by differential responses to $\mathrm{Ca}(2+)$ oscillation number. Dev Biol. 2002;250:280-91.

30. Foskett JK, White C, Cheung KH, Mak DO. Inositol trisphosphate receptor Ca2+ release channels. Physiol Rev. 2007;87:593-658.

31. Bonora M, Giorgi C, Bononi A, Marchi S, Patergnani S, Rimessi A, et al. Subcellular calcium measurements in mammalian cells using jellyfish photoprotein aequorin-based probes. Nat Protoc. 2013;8:2105-18.

32. Bogeski I, Al-Ansary D, Qu B, Niemeyer BA, Hoth M, Peinelt C. Pharmacology of ORAl channels as a tool to understand their physiological functions. Expert Rev Clin Pharmacol. 2010;3:291-303.

33. Carroll J. The initiation and regulation of $\mathrm{Ca} 2+$ signalling at fertilization in mammals. Semin Cell Dev Biol. 2001;12:37-43.

34. Thastrup O, Dawson AP, Scharff O, Foder B, Cullen PJ, Drobak BK, et al. Thapsigargin, a novel molecular probe for studying intracellular calcium release and storage. Agents Actions. 1989;27:17-23.

35. Kline D, Kline JT. Thapsigargin activates a calcium influx pathway in the unfertilized mouse egg and suppresses repetitive calcium transients in the fertilized egg. J Biol Chem. 1992;267:17624-30.

36. Carvacho I, Ardestani G, Lee HC, McGarvey K, Fissore RA, Lykke-Hartmann K. TRPM7-like channels are functionally expressed in oocytes and modulate post-fertilization embryo development in mouse. Sci Rep. 2016;6:34236.

37. Jin J, Wu LJ, Jun J, Cheng X, Xu H, Andrews NC, et al. The channel kinase, TRPM7, is required for early embryonic development. Proc Natl Acad Sci U S A. 2012;109:E225-33.

38. Lee DS, Goodman S, Dean DM, Lenis J, Ma P, Gervais PB, et al. Randomized comparison of T-type versus L-type calcium-channel blockade on exercise duration in stable angina: results of the Posicor reduction of ischemia during exercise (PRIDE) trial. Am Heart J. 2002;144:60-7.
39. Li P, Rubaiy HN, Chen GL, Hallett T, Zaibi N, Zeng B, et al. T-type Ca(2+) channel blocker mibefradil blocks ORAl channels via acting on extracellular surface. Br J Pharmacol. 2019;176(19):3845-56.

40. Martin RL, Lee J-H, Cribbs LL, Perez-Reyes E, Hanck DA. Mibefradil block of cloned T-type calcium channels. J Pharmacol Exp Ther. 2000;295:302-8.

41. Bezprozvanny I, Tsien RW. Voltage-dependent blockade of diverse types of voltage-gated $\mathrm{Ca} 2+$ channels expressed in Xenopus oocytes by the Ca2+ channel antagonist mibefradil (Ro 40-5967). Mol Pharmacol. 1995;48:540-9.

42. Prakriya M, Feske S, Gwack Y, Srikanth S, Rao A, Hogan PG. Orai1 is an essential pore subunit of the CRAC channel. Nature. 2006;443:230-3.

43. Prakriya M, Lewis RS. Store-operated calcium channels. Physiol Rev. 2015;95: $1383-436$.

44. Feske S, Gwack Y, Prakriya M, Srikanth S, Puppel SH, Tanasa B, et al. A mutation in Orai1 causes immune deficiency by abrogating CRAC channel function. Nature. 2006:441:179-85.

45. Bergmeier W, Stefanini L. Novel molecules in calcium signaling in platelets. J Thromb Haemost. 2009;7(Suppl 1):187-90.

46. Ferrer-Buitrago M, Bonte D, De Sutter $P$, Leybaert L, Heindryckx B. Single $\mathrm{Ca}(2+)$ transients vs oscillatory $\mathrm{Ca}(2+)$ signaling for assisted oocyte activation: limitations and benefits. Reproduction. 2018;155:R105-R19.

\section{Publisher's Note}

Springer Nature remains neutral with regard to jurisdictional claims in published maps and institutional affiliations.
Ready to submit your research? Choose BMC and benefit from:

- fast, convenient online submission

- thorough peer review by experienced researchers in your field

- rapid publication on acceptance

- support for research data, including large and complex data types

- gold Open Access which fosters wider collaboration and increased citations

- maximum visibility for your research: over $100 \mathrm{M}$ website views per year

At BMC, research is always in progress.

Learn more biomedcentral.com/submissions 